\title{
Expressed Emotion and Alexithymia in Mothers of Autistic Children
}

\author{
Kobra Abazari \\ Phd student in Department of psychology and Education of children with special needs, University of Isfahan, Iran \\ Email: kabazari@yahoo.com \\ Mokhtar Malekpour*
}

Professor in Department of psychology and Education of children with special needs, University of Isfahan

Email:m.mokhtar@edu.ui.ac.ir

\section{Amir Ghamarani}

Assistant professor in Department of psychology and Education of children with special needs, University of Isfahan, Iran Email: a.ghamarani@edu.ui.ac.ir

\begin{abstract}
Ahmad Abedi
Assistant professor in Department of psychology and Education of children with special needs, University of Isfahan, Iran Email: a.abedi@edu.ui.ac.ir
\end{abstract}

\section{Salar Faramarzi}

Assistant professor in Department of psychology and Education of children with special needs, University of Isfahan, Iran Email: s.faramarzi@edu.ui.ac.ir

\section{Doi:10.5901/mjss.2016.v7n4p}

\section{Abstract}

The birth of children with special needs brings about different problems such as stress and depression for their parents. Parental characteristics influence the way these parents interact with their children. 50 mothers of autistic children were picked out from 3 autism centers in Tehran. Furthermore, to compare their scores with those of typical children mothers, 50 mothers of normal children were randomly selected from pre-school and schools in Tehran and were considered as the control group. The findings revealed that there was no significant difference between autistic children mothers and normal children ones in terms of their alexithymia scores and its sub-components including identifying and describing feelings, and also emotionally-oriented thinking. However, a significant difference was observed between the two groups in terms of the expressed emotion and its sub-components including Emotional Over-Involvement (EOI) and criticism. Finally, the results uncovered that there was a correlation between Alexithymia scores of parents and their expressed emotion ones.

Keywords: Expressed Emotion, Alexithymia, Autism, mother

\section{Introduction}

Autism is a complex Neuro-developmental disorder characterized by difficulties in social interactions, communications, and also behavioral patterns, interests, and repetitive and limited activities (American Psychiatric Association, 2013). This problem not only affects the life of people all through their lives, but also influences their parents who play a significant role in their growth (Karst \& Van Hecke, 2012). The birth of children with special needs brings about different problems such as stress and depression for their parents (Eisenhower, Baker, \& Blacher, 2005). Parental characteristics affect the way these parents interact with their children (Aydin, 2015).

Studies have shown that the relationship between parent and child might considerably influences child's growth (Hooley \& Parker, 2006). Belsky (1984) contends that parents are, in fact, the main managers of emotion in families and the expressed emotion has currently been used to measure this important facet of families (quoted from Benson, et al. 2011). Expressed emotion refers to emotions and attitudes that are stated by members of family towards others (Laf \& 
Wagen, 1985 quoted from Benson, 2011). It might also be used as a means of examining the emotional status of parents and predicts the scope of psychological, medical, and growth disorders of autistic children (Benson, et al., 2011).

\section{Literature Review}

Reviewing the pertinent studies, it is understood that high expressed emotion is in accordance with the stress level of families which, in turn, could lead to the aggravation of the disorder and longer treatment period ( ${ }^{1}$. Hooley \& Gotlib, 2000; Pisholvaz, et al., quoted from Bader, et al., 2014). Researchers such as Eisenberg et al. (2001), Greenberg et al. (2006), Waser man et al. (2010), Benson et al. (2011), Griffith et al. (2014) have reported that the expressed emotion of autistic children's mothers is more than that of normal children's mothers and that is why autistic children have more behavioral and social problems.

Some research studies have also uncovered that expressed emotion leads to an increase in syndrome (Hooley \& Gotlib, 2000). High expressed emotion in families brings about negative verbal and non-verbal behaviors and children also produce such behaviors (Woo et al., 2004).

It might be generally asserted that family characteristics can affect the inability process of children (Greenberg et al., 2006) despite the few studies in terms of the nature and degree of influence of family environment on autistic children (Wilson, 2011). Similary, few studies have been conducted on the structure of expressed emotion in autistic children families (Orsmond et al., 2006) and no study has ever dealt with the factors affecting the expressed emotion of families. One factor that is likely to affect the emotional response and emotional regulation of person is their Alexithymia score.

The parents of autistic children function more weakly than normal children mothers (Whitehouse et al., 2010). They cannot focus very well on the intended topic in conversations; their personalities is less flexible and more unfriendly, and have problems in adaptation with changes (Gerts \& Bernier, 2011; Bishop, et al., 2004; Hurley, et al., 2007). As with autistic persons, autistic parents also have emotional disorders. They are largely indifferent to understanding others' feelings and cannot freely and easily express their own feelings (Korkmaz, 2010, Fazlioglu \& Yurdakul, 2009 quoted from Aydin, 2015; Zager et al., 2012). Such a status is referred to as Alexithymia that can play a role in the controlling of the expressed emotion of parents.

Alexithymia is a set of cognitive features that includes feeling knowing, problem in describing feelings of own and others, emotionally oriented thinking, and limited imaginative capability (Szatmary et al., 2008; Taylor, 2000). Compared with public population, autistic parents have more Alexithymia frequency (Szatmary et al., 2008). Adequate emotional performance is a must for health. The ability to identify, describe, and depict the feelings is a key for emotional decency which, in turn, results to health and improvement in intra and inter-person relationships (Eisenberg, et al., 2001; Shipman, 200 quoted from Telzer, et al. 2014).

Aydin (2015) compared the alexithymia status of autistic children parents and mentally-ill children parents. The results of this study which was carried out on 120 fathers and mothers revealed that there is no significant difference between the two groups as far as their Alexithymia status is concerned. In another study, 439 of autistic children parents and 45 Prader Willi children parents were compared. The findings indicated that autistic group gained higher scores on the Alexithymia questionnaire (Szatmari, 2008). In contrast, some studies do not support the impact of having autistic children in parents' adaptation (Montes \& Halterman, 2007). Despite the widespread interest in studying the autism phenotype, there is now no consensus on its definition (Scheeren \& Stauder, 2008).

Given the above-mentioned points on the effect of expressed emotion and Alexithymia on mental status and interpersonal relationships and on the treatment process of autistic children with high Alexithymia and expressed emotion and also the necessity of in Identifying autism phenotype, and also finding out about the factors and variables that are related to parents' expressed emotion, the present study addresses the following purposes: If the expressed emotion score and its' sub-components in autistic mothers is higher than that in normal mothers? If Alexithymia score and its' subcomponents in autistic mothers is more than that in normal parents? Is there any relationship between normal and autistic mothers in terms of their expressed emotion and Alexithymia? If it is possible to predict the expressed emotion of mothers from their Alexithymia scores?

\section{Method}

The present study made use of causal comparative method. The reason this method was used is that manipulation of the intended variables was not possible. Additionally, the researchers intended to reach the causes through dependent variable. The population is all normal and autistic children aged between 3 to 13 years old in Tehran in 2015. In this research study, which aimed at comparing the expressed emotion and Alexithymia status along with its sub-components 
among autistic children's mothers and normal children's ones, 100 normal and autistic children were picked out. To put it another way, in three autism centers that consented to cooperate with the researcher a questionnaire was distributed and 50 autistic children aged from 3 to 13 years old were selected. To examine their autism, both psychiatrists' examination and Giliam test were used. Finally, 50 autistic children whose mothers were consent to take part in the study were chosen and the mothers were asked to fill in related questionnaire (FTAS) and Family Questionnaire (FQ). Furthermore, in order to compare the expressed emotion and Alexithymia of autistic children mothers and those of normal children mothers, 50 normal children mothers whose children were in the range of 3 to 13 years old in age were randomly selected from preschools and schools of Tehran. Having interviewed them via DSM-V and Giliam questionnaire, the autism order in their children were rejected. These mothers, like the previous group mothers, also filled out the FQ and FTAS questionnaire. It should also be pointed out that the two groups mothers were homogeneous in terms of education degree, age, and economic level (intermediate economic level).

The intended criteria for taking part in the current study were: having the autism disorder based on DSM-V and Giliam questionnaire, lack of any severe physical disease such as hearing, sight, or kinestics problems, epilepsy, etc., parents should not have any severe psychological problems, the age range of 3-13 years old. In the case each of parents or children did not have these criteria, there were omitted from the study. Similarly, the criteria for normal children to participate in the study were: not suffering from autism based on psychiatrist's examinations and Giliam questionnaire, their parents do not have any severe psychological problems, their age should be between 3 and 13 years old, lack of any serious physical or mental disorder such as epilepsy, mental retardation, sight or hearing problems, etc.

\section{Instruments}

\subsection{Gilliam Autism Rating Scale (GARS):}

It is a checklist to specify people suffering from autism. It was developed in 1994 representing the features of autism on a 1094-person sample from 46 states in Colombia, Puerto Rico, and Canada. It has been developed based on the definitions of American Autism Association (1994) and American Psychiatry Association (APA) on the basis of DSM-IV. This scale is suitable for 3 to 22 years old persons and might be completed by parents or experts at school or at home. It involves four sub-scales each consisting of 14 items and each item is scored from 0 to 3 . The first sub-scale describes Stereotypes behaviors, kinestic disorders, and strange behaviors. The second sub-scale that is communication involves items 15 to 28 depicting the verbal and non-verbal behaviors which characterize autism. Social interaction is the third sub-scale which includes items 29 to 42 and the last sub-scale is growth disorders comprising items 43 to 56 . The maximum score for each of the three sub-scales of repetitive, communication, and social interaction is 3 and the minimum score is 0 . Receiving higher score signals a problem in the intended sub-scale and receiving lower scores indicate improvement in the sub-scale. The reliability of this instrument has been tested and confirmed in different studies. These studies have reported a $0.90 \mathrm{Cronbach}$ alpha for the Stereotypes behaviors, 0.89 for the communication, 0.93 for social interaction, 0.88 for growth disorders, and 0.96 for autism syndrome. In addition, the tool validity has also been confirmed by comparing it with other related instruments (Gilliam, 1995).

\subsection{FTAS:}

Alexithymia questionnaire is a paper-pencil scale which is based on self-report and developed by Bagby, Parker, and Taylor (1994). This self-report scale consists of 20 questions to evaluate Alexithymia. It comprises three sub-components of difficulty in identification of feelings (items $1,3,6,7,9,13$, and 14), difficulty in describing feelings (items 2, 4, 11, 12, 17), and concrete thinking $(5,10,8,15,16,18,19,20)$. It is in the 5-scale Likert format with 1 meaning absolutely disagree and 5 absolutely agree. A total score is also calculated for sum emotional Alexithymia. It is suitable for public and clinical samples and might be used individually and collectively. Questions 4, 5, 10,18, and 19 are also reversely scored. The sum score equal and higher than 61 is regarded as Alexithymia, score equal and lower than 51 is described as lack of Alexithymia, and the score between 56 and 60 is regarded as the probability of Alexithymia. In the Persian version of this scale, Cronbach alpha has been reported to be 0.85 and the three sub-scales as $0.82,0.75$, and 0.72 respectively which indicate a good internal consistency (Besharat, 2007). The present study reported a 0.63 Cronbach alpha for the instrument. 


\subsection{Family Questionnaire (FQ):}

It is a self-evaluation form to evaluate the expression of emotion in the families of psychiatric disorders developed by Wiedemann et al. in 2002. It involves 20 items. The responses are arranged in a four-scale Likert format from one (never) to four (always). It also comprises two sub-components of critical views and severe emotional involvement. In a study done on German group, its sum reliability was reported as 0.92 , the critical views reliability 0.84 , and that of severe emotional involvement as 0.91 . The instrument was also confirmed in terms of concurrent validity and showed a significant correlation with Kimberley Family interview (Wiedemann, 2002). In Iran, its total reliability has been reported to be 0.85 , and reliability of critical views and severe emotional involvement were reported to be 0.83 and 0.88 respectively (Khodabakhshi, 2005). In the present study, reliability was calculated by Cronbach alpha that showed that total reliability 0.84 , emotional involvement 0.77 and critical views 0.79 .

\section{Results}

The results and findings of this study has been presented by descriptive statistics. Table 1 presents the frequency, mean, and SD of the participants.

Table 1: Demographic variables of parents and normal and autistic children

\begin{tabular}{|c|c|c|c|c|c|c|}
\hline variables & groups & gender & Frequency & $\%$ & mean & SD \\
\hline \multirow{4}{*}{ Gender } & Autism & Girl & 12 & 24 & - & - \\
\hline & & Boy & 38 & 76 & - & - \\
\hline & Normal & Girl & 31 & 62 & - & - \\
\hline & & Boy & 19 & 38 & - & - \\
\hline \multirow{8}{*}{ Birth Order } & Autism & First & 28 & 56 & - & - \\
\hline & & Second & 12 & 24 & - & - \\
\hline & & Third & 10 & 20 & - & - \\
\hline & & Total & 50 & 100 & - & - \\
\hline & Normal & First & 35 & 70 & - & - \\
\hline & & Second & 14 & 28 & - & - \\
\hline & & Third & 1 & 2 & - & - \\
\hline & & Total & 50 & 100 & - & - \\
\hline \multirow{2}{*}{ Testees Age } & Autism & & & & 7.45 & 2.42 \\
\hline & Normal & & & & 6.77 & 2.98 \\
\hline Determination Age & Autism & & & & 3.32 & 1.42 \\
\hline \multirow{2}{*}{ Mother Age } & Autism & & & & 35.1 & 6.99 \\
\hline & Normal & & & & 31.42 & 4.68 \\
\hline \multirow{2}{*}{ Father Age } & Autism & & & & 40.34 & 7.15 \\
\hline & Normal & & & & 35.6 & 4.9 \\
\hline
\end{tabular}

In Table 2 the education degree of normal and autistic mothers has been compared.

Table 2: Educational Status of normal and autistic mothers

\begin{tabular}{|l|c|c|c|}
\hline Education Level & Frequency & Groups & $\%$ \\
\hline Lower than diploma & 15 & Autism & 30 \\
\hline Diploma & 29 & & 58 \\
\hline Associate & 4 & & 8 \\
\hline BA & 1 & & 2 \\
\hline MA & 1 & & 2 \\
\hline Lower than diploma & 13 & Normal & 26 \\
\hline Diploma & 31 & & 62 \\
\hline Associate & 2 & & 4 \\
\hline BA & 4 & & 8 \\
\hline MA & 0 & & 0 \\
\hline
\end{tabular}


Table 3 represents the descriptive scores (mean and SD) of Alexithymia and expressed emotion in the two autistic and normal children's mothers.

Table 3: Descriptive scores of Alexithymia and expressed emotion of autistic and normal children mothers

\begin{tabular}{|l|c|c|c|}
\hline Groups & mean & SD & sum \\
\hline Total Alexithymia Score & 50.9 & 13.25 & 50 \\
Autistic children mothers & 52.22 & 10.62 & 50 \\
Normal children mothers & 51.56 & 11.96 & 100 \\
Sum & & & \\
\hline Difficulty in Identification of feelings & 17.26 & 6.18 & 50 \\
Autistic children mothers & 17.58 & 5.55 & 50 \\
Normal children mothers & 17.42 & 5.85 & 100 \\
Sum & & & \\
\hline Difficulty in description of feelings & 12.32 & 3.87 & 50 \\
Autistic children mothers & 13 & 4.44 & 50 \\
Normal children mothers & 12.66 & 4.15 & 100 \\
Sum & & & \\
\hline Concrete thinking & 32.21 & 89.7 & 50 \\
Autistic children mothers & 64.21 & 68.3 & 50 \\
Normal children mothers & 48.21 & 13.6 & 100 \\
Sum & & & \\
\hline Total expressed emotion score & 56.58 & 7.08 & 50 \\
Autistic children mothers & & & \\
\hline Normal children mothers & 48.06 & 9.69 & 50 \\
\hline Sum & 52.32 & 9.47 & 100 \\
\hline Extreme emotional involvement & 30.88 & 4.37 & 50 \\
Autistic children mothers & & & \\
\hline Normal children mothers & 25.6 & 5.14 & 50 \\
\hline Sum & 28.24 & 5.44 & 100 \\
\hline Criticism & 25.7 & 4.6 & 50 \\
Autistic children mothers & & & \\
\hline Normal children mothers & 22.46 & 5.89 & 50 \\
\hline Sum & 24.08 & 5.51 & 100 \\
\hline
\end{tabular}

In order to investigate the significant or lack of significant difference between the two groups in terms of expressed emotion, MANOVA was used. $\mathrm{F}=15.44, \mathrm{Sig}=0 / 000, \mathrm{Eta}=0.24$ and power $=0.99$ gained in this test indicate that there was a difference between the two groups. Furthermore, in terms of the difference between them in terms of Alexithymia, $\mathrm{F}=0.26$, Sig $=0.008$, Eta $=0.84$ and power $=0.99$ uncover that there was no significant difference between the autistic and normal children's mothers. The significant difference between the two groups in total Alexithymia and its subcomponents, and also the total score of expressed emotion and its sub-components have been shown in Table 4.

Table 4: Difference of scores between autistic and normal children mothers in expressed emotion and Alexithymia

\begin{tabular}{|l|c|c|c|c|}
\hline Variables & F & sig & eta & Power \\
\hline Sum & 0.30 & 0.58 & 0.003 & 0.085 \\
Alexithymia & 0.074 & 0.78 & 0.001 & 0.058 \\
Difficulty in Identification of feelings & 0.66 & 0.41 & 0.007 & 0.12 \\
Difficulty in description of feelings & 0.06 & 0.79 & 0.001 & 0.058 \\
Concrete thinking & 25.16 & 0.000 & 0.20 & 0.99 \\
\hline Expressed emotion total score & 0.30 & 0.000 & 0.23 & 100 \\
Extreme emotional involvement & 9.37 & 0.003 & 0.087 & 0.85 \\
Criticism &
\end{tabular}

Investigation of the difference between sub-components of expressed emotion and Alexithymia of the mothers indicate that for the significant difference of means of the two groups in Alexithymia and its sub-components these scores were obtained: 0.58 for total Alexithymia, 0.78 for difficulty in feelings, 0.41 for difficulty in description of feelings, and 0.79 for 
concrete thinking. These results show lack of significant difference. In reverse, there is a significant difference between expressed emotion and its sub-components. The significance of 0.000 for the total expressed emotion and extreme emotional involvement, and criticism score of 0.003 indicate the significant difference.

Table 5: Parents Alexithymia and expressed emotion correlation

\begin{tabular}{|c|c|c|c|c|c|c|c|}
\hline Variables & & $\begin{array}{l}\text { Alexithymia } \\
\text { total score }\end{array}$ & $\begin{array}{l}\text { Identification } \\
\text { of feelings }\end{array}$ & $\begin{array}{l}\text { description } \\
\text { of feelings }\end{array}$ & $\begin{array}{l}\text { Concrete } \\
\text { thinking }\end{array}$ & \begin{tabular}{|c|} 
expressed \\
emotion total \\
score
\end{tabular} & $\begin{array}{c}\text { Extreme } \\
\text { emotional } \\
\text { involvement }\end{array}$ \\
\hline Identification of feelings & $\begin{array}{l}\text { Sig. Correlation } \\
\text { Score }\end{array}$ & $\begin{array}{l}* \star 0.81 \\
0.000\end{array}$ & & & & & \\
\hline description of feelings & $\begin{array}{l}\text { Sig. Correlation } \\
\text { Score }\end{array}$ & $\begin{array}{l}* 0.75 \\
0.000\end{array}$ & $\begin{array}{l}* * 0.66 \\
0.000\end{array}$ & & & & \\
\hline Concrete thinking & $\begin{array}{l}\text { Sig. Correlation } \\
\text { Score }\end{array}$ & $\begin{array}{l}\star \star 0.66 \\
0.000\end{array}$ & $\begin{array}{l}0.18 \\
0.06\end{array}$ & $\begin{array}{l}0.17 \\
0.08\end{array}$ & & & \\
\hline $\begin{array}{l}\text { expressed emotion } \\
\text { total score }\end{array}$ & $\begin{array}{l}\text { Sig. Correlation } \\
\text { Score }\end{array}$ & $\begin{array}{l}{ }^{\star *} 0.33 \\
0.001\end{array}$ & $\begin{array}{l}\star \star 0.29 \\
0.003 \\
\end{array}$ & $\begin{array}{l}\star \star 0.37 \\
0.000 \\
\end{array}$ & $\begin{array}{l}0.11 \\
0.26 \\
\end{array}$ & & \\
\hline $\begin{array}{l}\text { Extreme emotional } \\
\text { involvement }\end{array}$ & $\begin{array}{l}\text { Sig. Correlation } \\
\text { Score }\end{array}$ & $\begin{array}{l}{ }^{* \star} 0.3 \\
0.002\end{array}$ & $\begin{array}{l}* * 0.27 \\
0.005\end{array}$ & $\begin{array}{l}\star \star 0.33 \\
0.001\end{array}$ & $\begin{array}{c}0.1 \\
0.29\end{array}$ & $\begin{array}{l}* * 0.86 \\
0.000\end{array}$ & \\
\hline Criticism & $\begin{array}{l}\text { Sig. Correlation } \\
\text { Score }\end{array}$ & $\begin{array}{l}\star \star 0.27 \\
0.007\end{array}$ & $\begin{array}{c}* 0.23 \\
0.0 .017\end{array}$ & $\begin{array}{l}\star \star 0.31 \\
0.002\end{array}$ & $\begin{array}{l}0.09 \\
0.37\end{array}$ & $\begin{array}{l}* \star 0.86 \\
0.000\end{array}$ & $\begin{array}{l}* * 0.49 \\
0.000\end{array}$ \\
\hline
\end{tabular}

** Correlation is significant at 0.01

* Correlation is significant at 0.05

The results of Table 5 showed that to examine the relationship between Alexithymia score and expressed emotion score Pearson test was used which, in turn, uncovered that there is significant correlation between Alexithymia score (0.33), extreme emotional involvement score (0.3), and criticism score (0.27). Additionally, there is a significant difference between identification and description of feelings and the total expressed emotion with correlation scores of 0.29 and 0.37 respectively, identification and description of feelings and extreme emotional involvement with score of 0.27 and 0.33 respectively, and identification and description of feelings and criticism with scores of 0.23 and 0.31 respectively. However, no significant correlation was observed between concrete thinking and total expressed emotion. Finally, the regression analysis for predicting the total expressed emotion score from Alexithymia revealed that it is possible to predict the mothers' expressed emotion by Alexithymia (Beta $=0.33, \mathrm{t}=3.46$, and sig $=0.001$ ).

\section{Discussion and Conclusion}

This study was carried out with the purpose of investigating the expressed emotion and Alexithymia differences and also the relationship of these two variables in mothers of normal and autistic children aged between 3 to 13 years old in Tehran. The findings of the study indicated that there was a significant difference between the two groups of parents in terms of the total expressed emotion and its sub-components. That is, the mothers of autistic children had more criticism and extreme emotional involvement compared to those of normal children. This finding is in accordance with what has been reported in studies such as Eisenberg et al. (2001), Greenberg et al. (2006), Waserman et al. (2010), and Benson et al. (2011).

Similarly, Griffith (2014) reported that mothers behave less warmly and more critically against their autistic children but no difference was observed among mothers in terms of their extreme emotional involvement with autistic children and normal children (Griffith et al., 2014). The difference in the results of the present study and that of Griffith et al. (2014) might be discribed to not only the different population and sample but also the different instruments utilized in the two research works. In other words, the current study made use of FQ (that is a paper and pencil questionnaire) while the other one employed FMSS questionnaire which is based on parents' verbal speech and in this questionnaire parents are asked to take about their children and then based on their speaking the extent of criticism and emotional involvement is measured (Benson, et al., 2011).

The other objective of the present research study was to make a comparison between normal and autistic children's mothers in terms of Alexithymia. The obtained findings revealed that there was no significant difference between the two groups of parents in terms of their Alexithymia and its sub-components including difficulty in identification of feeling, difficulty in description of feeling, and concrete thinking. This result was in sharp contrast with 
result of other studies such as Krukmaz (2010), Fozil Oghlu and Yardakul (2009), Wing (2012) quoted from Aydin (2015), Zager (2012), and Szatmari et al. (2008).

Szatmari et al. (2008) contended that compared to public population, autistic children's mothers have more Alexithymia frequency. This research was conducted on 439 autistic children and 45 mother of PraderWilli disorder. The study showed that the former mothers received higher Alexithymia scores than the latter ones. In this study, both father and mother were studied and both of them received higher Alexithymia scores than the PraderWilli ones. But in this present study only the mothers were studied. According to some studies Alexithymia is usually higher in men than women (Sarak, 2013 quoted from Aydin, 2015). Jokoma et al (2003) also reported that $5.3 \%$ of women and 9.4\% of men have Alexithymia. The Szatmari's study also reported that the children of those fathers who had higher Alexithymia had more repetitive behaviors. One of the main reasons for the difference of results between the present study and those of Szatmari is that in this study only mothers were studied.

Another reason for the difference of the present research results with those of some other studies might be the cultural difference. The present research was conducted in Iranian context in Tehran province. However, to investigate more accurately the impact of cultural difference, further and studies with more samples is required. In addition to abovecited points, in the present study like all other pertinent studies, Toronto Alexithymia Scale was used. The feature of this questionnaire is that it is a paper and pencil questionnaire which is filled out in a self-report way. It has been contended that those persons who have difficulty in identifying and describing their problems but have good perspective about their problems can fill out the questionnaire better than those who the same people but with lower attitude (Szatmari et al. 2008). Given this point, probably one reason that no significant difference was found between the normal and autistic children's mothers is the same issue that is low level of attitude toward the problem in autistic children's mothers. There are, however, some other studies in which, like the present one, no significant difference for the same variables has been reported. As an example, Aydin (2015) studied the Alexithymia status between parents of normal and mental retarded children. The study reported no significant difference between the two groups of study in terms of Alexithymia. It should also be pointed out that in none of the studies mentioned in this study the Alexithymia of normal and autistic children's mothers were compared.

The third purpose of this study was to shed light on the relationship between expressed emotion of the mothers and their Alexithymia. And if it is possible to predict their expressed emotion by their Alexithymia or not. The results of the study showed that there is a significant (but slight) relationship between the total score of Alexithymia and total score of expressed emotion, emotional involvement and criticism. Similarly, there is a significant relationship between identification and description of feelings and total score of expressed emotion, extreme emotional involvement and criticism. But no significant relationship was observed between concrete thinking and total score of expressed emotion. Although there has been carried out no study dealing with the relationship of expressed emotion and Alexithymia among autistic and normal children mothers. Luminet et al (2004) and also Politoz et al (2011) stated that there are differences between Alexithymia and non-Alexithymia persons in terms of expressed emotion. Additionally, according to Eisenberg et al. (2001) and Shipman (2001), emotional decency leads to health and improvement in intra- and interpersonal relationships (quoted from Telzer et al., 2014). Some studies, however, point out that expressed emotion of parents hinges on children conditions. However, it is not yet clear what children-related factors might result to children high expressed emotion. Some studies show that the expressed emotion of autistic parents are due to their autistic children conditions but it is not exactly clear what features are influential in this regard (Saikojio et al, 2007 quoted from Piss, 2012).

One of the limitations of the present study was the small number of participants largely due to lack of cooperation of autism centers. Therefore, it is suggested that further studies with larger sample sizes and in other contexts be conducted. Another limitation of the study was related to the mere employment of self-report Toronto questionnaire to measure Alexithymia and because lower level of perception towards emotional status might influences the results, it is suggested that in future studies other methods such as interview be also used. Moreover, the other limitation of the study was lack of cooperation of fathers in filling out the questionnaire and because the results of Alexithymia might be different between mothers and fathers, it is recommended to make a comparison between mothers and fathers in future research projects. Furthermore, given the results of this study (correlation between Alexithymia and expressed emotion and also predictability of expressed emotion based on Alexithymia), other studies are suggested to be carried out in which reduction of Alexithymia score of parents for its impact on their expressed emotion is looked into. Finally, it is also suggested that other factors that might lead to increase of expressed emotions of parents be studied so that appropriate programs might be compiled to decrease the expressed emotion of parents and improve children's treatment trend. 


\section{References}

American Psychiatric Association.(2013). DSM-V-TR1 diagnostic and statistical manual of mental disorders. Arlington, VA: APA.

Aydın, A. (2015). A comparison of the alexithymia, self-compassion and humor characteristics

Of the parents with mentally disabled and autistic children.Procedia - Social and Behavioral Sciences 174. $720-729$.

Bader, S. H. Barry, T. D., \&Hann, J. H. (2014).The Relation between Parental Expressed Emotion and Externalizing Behaviors in Children and Adolescents with an Autism Spectrum Disorder.Focus on Autism and Other Developmental Disabilities. 44(11.

Benson, P. Daley, Dave. Karlof, K. Robison, D. (2011).Assessing expressed emotion in mothers of children with Autism.SAGE Publications and the National Autistic Society.15(1) 65-82; 3527771362-3613.doi: 10.1177/1362361309352777

Besharat, M. A. (2007). Reliability and factorial validity of a Farsi version of the Toronto Alexithymia Scale with a sample of Iranian students.Psychological Reports, 101, 209-220.doi: 10.2466/pr0.101.1.209-220

Bishop, D., Maybery, M., Maley, A., Wong, D., Hill, W. and Hallmayer, J. (2004). Using self-report to identify the broad phenotype in parents of children with autistic spectrum disorders: a study using the autism-spectrum quotient. Journal of Child Psychology and Psychiatry, 45(8),1431-1436. DOI: 10.1111/j.1469-7610.2004.00325.x

Eisenberg, N., Gershoff, E. T. Fabes, R. A. Shepard, S. A. Cumberland, A. J. . Losoya, S. H... Guthrie, I. K and Murphy, B. C. (2001). Mothers' Emotional Expressivity and Children's Behavior Problems and Social Competence: Mediation through Children's Regulation. Developmental Psychology. 37. 4, 475-490.

Eisenhower, A. S., Baker, B. L., \&Blacher, J. (2005). Preschool children with intellectual disability: Syndrome specificity, behavior problems, and maternal wellbeing. Journal of Intellectual Disability Research, 49(Pt 9), 657-671.

Gerdts, J. and Bernier, R. (2011).The broad autism phenotype and its implications on the etiology and treatment of autism spectrum disorders. Autism Research and Treatment, Article ID 545901, 1-19.doi: 10.1155/2011/545901

Gilliam JE. Gilliam autism rating scale GARS. (1995 ).Austin, TX: Pro-Ed (Firm).

Greenberg, J.S., Mailick Seltzer, M., Hong, J., \&Orsmond, G.I. (2006) 'Bidirectional Effects of Expressed Emotion and Behavior Problems and Symptoms in Adolescents and Adults with Autism', American Journal on Mental Retardation 111: 229-249.

Griffith G. M, Hastings, R. P. Petalas, M. A. \& Lloyd, T. J. (2014) .Mothers expressed emotion towards children with autism spectrum disorder and their siblings. Journal of Intellectual Disability Research. P: 1-8. DOI: 10.1111/jir.12178

Hooley, J. M., \&Gotlib, I. H. (2000). A diathesis stress conceptualization of expressed emotion and clinical outcome. Applied and Preventative Psychology, 9, 135-151.

Hooley, J.M., \& Parker, H.A. (2006). Measuring expressed emotion: an evaluation of the shortcuts. Journal of Family Psychology, 20(3), 386-396.

Hurley, R. S. E., Losh, M., Parlier, M., Reznick, J. S. and Piven, J. (2007).The broad autism phenotype questionnaire.Journal Autism Developmental Disorders, 37, 1679-1690. 10.1007/s10803-006-0299-3

Joukamaa, M., Kokkonen, P., Veijola, J., Laksy, K., Karvonen, J. T., Jokelainen, J. et al. (2003). Social situation of expectant mothers and alexithymia 31 years later in their offspring: A prospective study. Psychosomatic Medicine, 65, 307-312

Karst, J. S., \& Van Hecke, A. V. (2012).Parent and family impact of autism spectrum disorders: A review and proposed model for intervention evaluation. Clinical Child and Family Psychology Review, 15(3), 247-277.doi: 10.1007/s10567-012-0119-6.

Khodabakhshikoolayi A. (2007).Comparethe effectiveness offamily"model of familymanagement" and"psycho-educational McFarlane" to reducerelapseinschizophreniapatients' mothers, mothersexpressed emotionandpsychological pressure onthem. Phd thesis,. Iran, Tehran, Allametabatabayi university. [in Persian].

Luminet, O., Rime, B., Bagby, R. M., \& Taylor, G. J. (2004).A multimodal investigation of emotional responding in alexithymia. Cognition and Emotion, 18, 741-766. DOI: 10.1080/02699930341000275

Montes, G., \&Halterman, J. S. (2007). Psychological functioning and coping among mothers of children with autism: A population-based study. Pediatrics, 119, e1040-e1046.

Orsmond G. I., Seltzer M. M., Greenberg J. S. \& Krauss M. W. (2006) Mother-child relationship quality among adolescents and adults with autism. American Journal of Mental Retardation 111, 121-37.

Parker, J. D. A., \& Taylor, G. J. (1994).The twenty-item Toronto Alexithymia Scale-I.Item selection and cross-validation of the factor structure.Journal of Psychosomatic Research, 38, 23-32.

Peace N. (2012). Expressed Emotion and Adjustment in Families with Children with Autistic Spectrum Conditions.PHDthesis, UNIVERSITYOF SOUTHAMPTON.38-47.

Pollatos, O., Werner, N. S., Duschek, S., Schandry, R., Matthias, E., Traut-Mattausch, E., et al. (2011). Differential effects of alexithymia subscales on autonomic reactivity and anxiety during social stress. Journal of Psychosomatic Research, 70, 525-533. doi: 10.1016/j.jpsychores.2010.12.003

Scheeren, A. M., \&Stauder, J. E. (2008). Broader autism phenotype in parents of autistic children: Realityor myth? Journal of Autism and Developmental Disorders, 38, 276-287.

Szatmari P. Georgiades S. Duku E. Zwaigenbaum L. Goldberg J. Bennett T. (2008). Alexithymia in Parents of Children with Autism Spectrum Disorder.J Autism DevDisord. 38:1859-1865.

Taylor GJ. (2000). Recent developments in alexithymia theory and research. Can J Psychiatry, 45:134-142.doi: 10.1007/s10803-0080576-4

Telzer E. Qu Y. Goldenberg D.Fuligni A. Galván A. and Lieberman M. (2014). Adolescents' emotional competence is associated with parents' neural sensitivity to emotions. Frontiers human neuroscience.Volume 8.P 558.doi: 10.3389/fnhum.2014.00558 
Wasserman, S. Mamani, A. W. Mundy, P .(2010). Parents' criticisms and attributions about their adult children with high functioning autism or schizophrenia.SAGE Publications and the National Autistic Society.14(2) 127-137doi: 10.1177/1362361309354757

Wiedemann, G., Rayki, O., Feinstein, E., \&Hahlweg, K. (2002). The family questionnaire: Development and validation of a new selfreport scale for assessing expressed emotion. Psychiatry Research, 109, 265-279.

Whitehouse, A.J.O., Coon, H., Miller, J., Slisbury, B. and Bishop, D.V.M. (2010).Narrowing the broader autismphenotype: A study using the communication checklist-adult version.Autism, 14(6), 559-574.doi: 10.1177/1362361310382107

Wilson, R \& Hughes, C. (2011).Assessing Expressed Emotion in parents in association with children's social competence,language ability and their understanding of others. University of Cambridge, 1-28.

Woo, S. M., Goldstein, M. J., \&Nuechterlein, K. H. (2004). Relatives' affective style and the expression of subclinical psychopathology in patients with schizophrenia.Family Process, 43, 233-247. DOI: 10.1111/j.1545-5300.2004.04302008.x

Zager, D., Wehmeyer, M. L. and Simpson, R. L. (2012).Educating students with autism spectrum disorders: Research-based principles and practices.Bregmen, J. D., Higdon, C. Definitions and clinical characteristics of autism spectrum disorders. New York: Routledge. 10.1080/09687599.2012.739363 